\title{
Introduction \\ Taking stock: research and methodology in Community Interpreting
}

\author{
Erik Hertog \\ Lessius University College \\ Bart van der Veer \\ Hoger Instituut voor Vertalers en Tolken - University College Antwerp
}

Many colleagues would argue that Community Interpreting (CI) came of age as an academic and professional discipline with the first Critical Link Conference in Geneva Park, Canada, in 1995. This first major international gathering of practitioners, trainers and researchers in the field of CI provided a forum for the two hundred and fifty participants for a stimulating exchange of ideas about the age-old, and yet so very new discipline of interpreting in legal, health and social service settings. (See Carr and Roberts 1997).

As a number of surveys in this volume amply show, of course there was a great deal of significant research in CI prior to the 1990s. Nevertheless, it is this decade that saw the publication of those seminal studies which would define the research paradigm that really opened up the potential of $\mathrm{CI}$ as a fully-fledged academic discipline.

In 1990 Susan Berk-Seligson published her landmark study of English-Spanish interpreting in U.S. courts - The Bilingual Courtroom launching in its wake a stream of discourse-oriented studies, culminating recently in Sandra Hale's The Discourse of Court Interpreting (2004). This approach was taken further and refined in the work of Cecilia Wadensjö (1992, repr. 1998), who focused on the face-to-face dialogic and joint interactivity of the participants in her analysis of a number of medical, police and asylum hearings as interpreted events. Her analysis showed that this dialogic interactivity had demonstrably important consequences for the role, positioning and overall performance of the interpreter. It is this seminal study that perhaps more than any other defined what Franz Pöchhacker called the 'dialogic discourse-based interaction' paradigm', (Pöchhacker 2004:79) which for most scholars and analysts still defines the fundamental research method in CI and still inspires current research (Angelelli 2004). Similar ground-breaking work went on in Sign Language research in the 1990s, and towards the end of the decade particularly the work of Melanie Metzger (Sign Language Interpreting: Deconstructing the Myth of Neutrality, 1999) and Cynthia Roy (Interpreting as a Discourse Process, 2000) had a great impact because they succeeded in bridging the gap between the specificity of Sign Language research and the by then mainstream CI research paradigm. A final example in this perhaps rather eclectic survey is the study by Robert Barsky (Constructing a Productive Other, 1994) of interviews with applicants for refugee status in Canada, highlighting the structural and 
institutional environments in which such interpreting assignments take place. His study has opened up the path for an extremely interesting line of research in $\mathrm{CI}$, that of critical discourse analysis, which is currently being combined with aspects of politeness theory and face-saving and face-threatening strategies and which underlies the interesting work of e.g. Pöllabauer 2005 and Pöllabauer, Inghilerri and Mason all in this volume.

At the same time, the leading academic journals in interpreting began to pay explicit attention to $\mathrm{CI}$ and in Meta, Target, Interpreting or The Translator (see, for example, The Translator 5:2, 1999, on Dialogue Interpreting), many articles and indeed special issues were devoted to this hitherto rather neglected branch of interpreting studies.

No doubt the successive and successful Critical Link Conferences (Vancouver, Montreal, Stockholm and Sydney in 2006) and this expanding academic research interest in CI fed on each other and fuelled each other's momentum. Hence, consequently, there can be no denying that by now CI has established itself as an inextricable part of Interpreting Studies (see Pöchhacker: 2004, passim) and may now well be its most active research field, with a significant input to the discipline as a whole. There is now in CI research a very impressive body of scholarly, academic research, taking its inspiration from both 'translatology' theories as well as related disciplines such as discourse analysis, pragmatics, critical conversation analysis, cultural studies, sociology, psychology, etc. and as a result, immense gains have been made in our understanding of the theory and practice of CI. This interdisciplinarity as well as its focus on discourse, interactivity and socioenvironmental factors, are what make CI research so challenging and fruitful within the broad community of Interpreting Studies.

During this same period, CI research also began to have a considerable impact beyond 'academia'. Many contributions to CI research still (need to) focus on immediate practical challenges such as training or professional policies and practices because they form the cornerstones of the professionalization of the work of the community interpreters. (See Mikkelson 1996 and 1999; Pöchhacker 1999; and Roberts 2002) And although a lot still needs to be done, there is no doubt that many policies, regulations and practices in the field of the law, immigration and asylum, medicine, public services etc. around the world, have been profoundly influenced by the results of the research carried out in CI. The European Court of Human rights has decided important case-law on the provision and quality of legal interpreting, while the European Union is in the process of developing common minimum standards in this field in all member states. Most countries now have a patients' charter that specifically includes the right to understand, be treated and be able to give 'informed consent' to treatment in a language the patient can understand. In a similar vein, asylum and refugee authorities have become sensitive to power and gender issues in interpreting, federal and state U.S. authorities require competence-based certification for registration, court cases go on appeal and hospitals have been forced to compensate for malpractices on the grounds of deficient interpreting quality. 
Therefore, now roughly ten years after Geneva Park, with this impressive record of scholarly achievement behind us and with the Critical Link 5 conference before us, the time seems appropriate to step back and take stock of CI research.

From the beginning, it has been the editors' intention to devote the 2006 special issue of Linguistica Antverpiensia New Series not only to what has been done and achieved but also to survey and analyze the methodological issues in CI research. At the same time, the concerted effort of analysis and evaluation of this research by the contributors is also intended to offer a unique opportunity, especially to new and aspiring researchers in the field, to get to know the history of research in CI, learn from its methodological strengths as well as weaknesses and identify the future course the discipline might take.

In our call for papers we listed a number of issues we would have liked to see addressed. Their somewhat revised enumeration here - in response to the contributions received - provides the conceptual framework of this volume.

Our first question to the researchers was, whether CI research can (already?) be surveyed in one or more paradigms? Can one, in other words, at this stage begin to sketch an early history of CI research? And, how does research in CI relate to research paradigms and issues in the wider fields of 'Interpreting' and 'Translation Studies'?

These questions are explicitly addressed in the first part 'Exploring the Paradigm' by Mette Rudvin and Hildegard Vermeiren. In this part, the authors set out to trace some of the epistemological shifts that have determined the recent paradigmatic shifts in language studies and show how they trickle down to the level of ethics and role-definition in CI. This part also pays particular attention to the fuelling contribution of such related disciplines as discourse analysis, pragmatics, cultural studies, sociology, psychology, etc..

However, it seemed interesting to include here two complementary approaches, the first of which is a theoretical contribution by Moira Inghilerri. She provides an outline of a sociological and linguistic-ethnographic perspective applied to CI to consider how relevant macro-structural features impact on the interpreting activity, how interpreters as pivotal players are caught up in larger social configurations of power and control. Her approach charts the course theoretical reflections on CI might take in the future. The second complementary contribution is by Makiko Mizuno who surveys in her article the concrete 'practical' process of development of CI research in a given country, thus linking practice and policy to ongoing research.

Of course, there is also an obvious need to reflect on the validity of the methodologies that are commonly used in CI research. CI research has, unfortunately, not been without its occasional pitfalls of oversimplification, questionable research premises, hasty extrapolations, in short, unsound methodology and research practices. 
Therefore, the second part on 'Research methodologies in CI', with contributions from Carmen Valero-Garces, Ian Mason and Erik Hertog, Jan Van Gucht and Leen de Bontridder, addresses these fundamental issues. Carmen Valero-Garces analyzes the specific contribution applied linguistics has made to the study of CI. Ian Mason's paper is methodologically interesting as it suggests a way forward for pragmatics-sensitive research into actual participant moves in CI. His analyses relate participants' utterances to the broader issues of role, power distribution and norms, thus simultaneously raising broad and general methodological issues about the analyst's imagined reconstruction of context and intentionality. But as some contributors in this volume continue to stress, CI research is often found lacking in methodological coherence, all too often misusing research designs of an essentially exploratory nature to generate broad sweeping conclusions at medium or even grand theory level, the conclusions thus typically lacking in falsifiability or even validity. Erik Hertog, Jan Van Gucht and Leen de Bontridder first discuss general principles of scientific research in CI, including the widespread and often questionable use of the ubiquitous questionnaire or interview. Based on a number of concrete studies which they carried out, they go on to suggest an overall and generally applicable methodology for research into CI.

And then there are the individual researchers, landmark studies and specific contexts. Which indeed have been the seminal groundbreaking publications in the various contexts of CI such as legal, social or medical interpreting? Why, and what has been their impact? The contributors focus here on the methodology, research results and validity of the important studies in their respective fields and try to gauge their influence by assessing the impact of these works on other publications. These contributions focusing on a particular area of CI make up the bulk of this volume and provide, each of them, an illuminating, critical survey not only of the landmark studies but of the research carried out and methodology/ies used in that field.

In the third part of this volume, on 'Medical Interpreting', Franz Pöchhacker reviews the evolution and main strands of research on interpreting in healthcare. He describes the literature from the point of view of different disciplinary perspectives but also surveys it in terms of thematic orientation, focusing on the interpreting product, interpreter performance, communicative practices and the provision of care. This thorough, sweeping analysis is followed by Hanneke Bot's contribution which hones in on a very specific and demanding challenge in CI, i.e. interpreting in mental health settings. She sets out to answer the question how mental health talk differs from dialogue in other CI areas and to what extent the interpreter 'influences' the content of the communication as a result of his (possible lack of) knowledge of the type of communication at hand, the institutional setting, the specific linguistic characteristics of the type of talk and the personal ideas, norms and values which he brings to the assignment. Alexander Bischoff and Diana Abraham and Marco Fiola, on the other hand, widen the scope in their contributions and analyze the research in medical 
CI that relates provision and quality of CI service to the quality of the medical service provided and health policy-making in general. According to Alexander Bischoff, at a time of growing cultural and linguistic diversity which requires healthcare systems to implement high-quality professional interpreter services that ensure effective communication with foreign-language speaking patients, it is crucial to understand the potential impact interpreters can have in clinical outcomes and how the quality and satisfaction in communication can be improved. Changes in the quality of interpreter-mediated communication can be monitored and shown to have a beneficial impact on the quality of care. Diana Abraham and Marco Fiola, wrestling with similar issues, take as their starting-point a recently completed research study that suggests that a paradigm shift may be operating in the Canadian healthcare sector and that instead of seeing language barriers solely as a human rights issue, with all its impending obstacles and hurdles to satisfactory implementation, language barriers are increasingly being considered from a risk-management perspective and therefore 'worth' the quality effort and investment.

In the fourth part dealing with 'Legal Interpreting', Sandra Hale as the first contributor provides a survey of CI in the legal services, including police interviews, lawyer-client consultations, hearings and court sessions, etc. As she points out, the vast majority of CI research in this field has concentrated on the discourse of the courtroom, which has served as the theoretical basis for the training and study of court interpreting in general. Unfortunately, fewer studies have focused on other contexts of legal interpreting, such as police interviews and interrogations, or on other interesting lines of research such as non-linguistic aspects of the interpreted event (e.g. role perceptions). Sonja Pöllabauer takes a bibliometrical approach to the research in immigration, asylum and police settings, quantitatively charting the body of research according to a number of different parameters but also investigating the different analytical approaches that have been used to analyze these interpreter-mediated interviews.

The fifth part on 'Sign Language Interpreting', of course, pervades each of the above research questions. But given the seminal and influential contribution of Sign Language CI research, both in academia and in shaping training, professional practices and institutional provisions, we felt that SL deserved a special attention.

Nadja Grbić and Sonja Pöllabauer first focus on the similarities as well as the differences between spoken and signed language CI and go on from there to survey the history of research and the various examples of research methods that have been applied in this field. Melanie Metzger meticulously analyzes the evolution of CI research in Sign Language during the past four decades, thus covering a broad range of scholars, countries and topics, from analyses of cognitive processes to analyses of the management of the interpreted event, whether in-person or via technology. The seminal contributions to CI in Sign Language are finally contextualized within the larger framework of CI research in general. The final contribution in this part, appropriately enough from the home country of this journal, Flanders, 
is by Mieke Van Herreweghe and Myriam Vermeerbergen. They provide a similar but nationally focused overview of 25 years of CI in the Deaf Community in Flanders. This research has not only clearly influenced SL interpreter training programmes, it has also had an important impact on the professionalization of the interpreters and indeed on the empowerment of the Deaf community as such.

But given the times we are all living and working in, surely there is a need for new methodologies as CI via new 'channels' is increasing and new technologies are becoming current, such as telephone, videophone or internet interpreting.

Therefore, in the last part we focus on 'Remote CI'. Tim Connell argues that CI should indeed look to the new technologies in search for solutions to particular problems and to provide more efficient services. However, that this trend will have a considerable impact on both practical (training, cost-management, etc.) and ethical aspects of the interpreter's work, goes without saying. Leong Ko too is convinced that remote CI is becoming increasingly widespread. Nevertheless, this area is under-researched and the limited and all too often subjective research findings do not accurately reflect the real situation, according to Leong Ko. Hence the call for long-term, empirical studies to address the interpreting issues, such as quality, stress, etc., involved in these new forms of CI.

Finally, we need to come full circle and return after all this inspiring research and scholarship to the reality and challenges of the police interview room, the hospital, the school, the asylum hearing office, etc. , in other words, to the world of the practicing quality CI professional.

Hence a final caveat by Ann Corsellis. While there is indeed a pressing need to provide academic underpinning to CI, one should take care, she argues, to engage throughout in a respectful way with the professional practitioners as well as with both members and users of the public services to gather adequate and reliable information, to develop interdisciplinary understanding and, wherever possible, improve practice. Rigorous scientific responsibility and methodologies and wide dissemination of the results should prevent research from drifting off into its academic ivory towers, with all too little regard for the pressing concerns that practitioners wrestle with in their daily practice.

It has been the editors' aim to make this special issue of Linguistica Antverpiensia New Series on 'Research and Methodology in Community Interpreting' a publication that surveys and evaluates not only past research output, both qualitatively and quantitatively, but at the same time also one that charts new courses for the future, especially for new aspiring researchers in CI. We look to them with great expectations but also with confidence, to make the next decades in CI research as fruitful as the ones surveyed here. 


\section{Bibliography}

Angelelli, C. (2004). Re-visitng the Role of the Interpreter: A Study of conference, court and medical interpreters in Canada, Mexico and the United States. Amsterdam-Philadelphia: John Benjamins.

Barsky, R.F. (1994). Constructing a Productive Other. Amsterdam-Philadelphia: John Benjamins.

Berk-Seligson, S. (1990). The Bilingual Courtroom. London: University of Chicago Press.

Carr, S. et al.,eds. (1997). The Critical Link: Interpreters in the Community. AmsterdamPhiladelphia: John Benjamins.

Hale, S. (2004). The Discourse of Court Interpreting. Amsterdam-Philadelphia: John Benjamins.

Metzger, M. (1999) Sign Language Interpreting: Deconstructing the Myth of Neutrality. Washington: Gallaudet Press.

Mikkelson, H. (1996). "Community Interpreting: An Emerging Profession”. Interpreting 1 (1), 125 29.

Mikkelson, H. (1999). "The Professionalization of Community Interpreting". Journal of Interpretation 1999, 119-33.

Pöchhacker, F. (1999). "Getting Organized: The Evolution of Community Interpreting". Interpreting 4 (1), 125-40.

Pöchhacker, Franz. (2004). Introducing Interpreting Studies. London: Routledge.

Pöllabauer, S. (2005). "I don’t understand your English, Miss. Dolmetschen bei Asylanhörungen. Tübingen: Gunther Narr Verlag

Roberts, R. (1997). "Community Interpreting Today and Tomorrow". In: Carr, S. et al. (eds.). The Cticial Link: Interpreters in the Community. Amsterdam-Philadelphia: John Benjamins, 726.

Roberts, R. (2002). "Community Interpreting: A Profession in Search of its Identity”. In: Hung, E. (ed.). Teaching Translation and Interpreting 4. Amsterdam-Phildalephia: John Benjamins, 157-175.

Roy, C. (2000). Interpreting as a Discourse Process. Oxford: Oxford University Press.

Wadensjö, C. (1998). Interpreting as Interaction. London: Longman. 